58

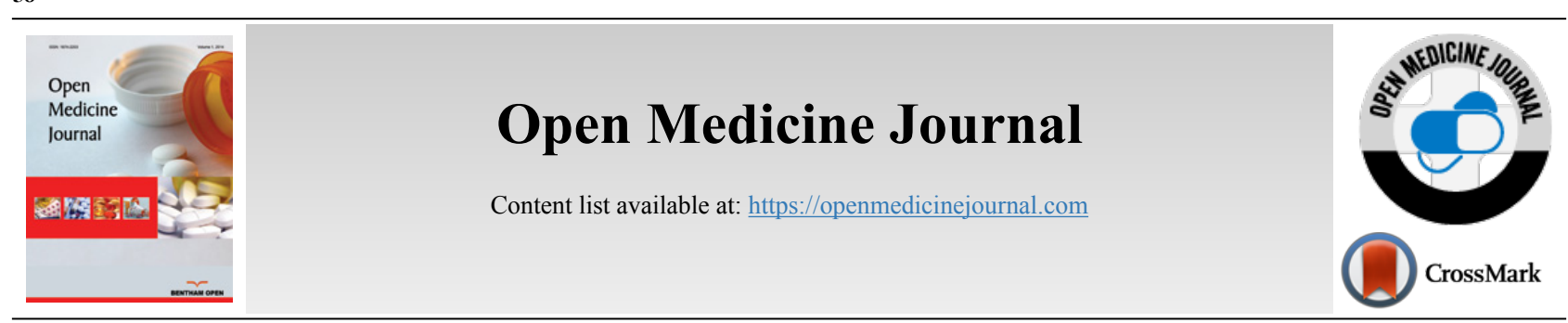

RESEARCH ARTICLE

\title{
Stroke Severity and Outcomes in Patients with and without Atrial Fibrillation
}

\author{
Augustė Ragelyte ${ }^{1, *}$, Gabrielė Rudokaite ${ }^{1,2}$, Diana Žaliaduonytė-Pekšiené ${ }^{2}$ and Vytautas Zabiela ${ }^{2,3}$ \\ ${ }^{1}$ Lithuanian University of Health Sciences Faculty of Medicine, Lithuania \\ ${ }^{2}$ Lithuanian University of Health Sciences Department of Cardiology, Lithuania \\ ${ }^{3}$ Kaunas Region Society of Cardiology, Lithuania
}

\begin{abstract}
:
Background

Atrial fibrillation (AF) is a major risk factor for ischemic stroke. It is important to verify the effect of AF on the outcomes of stroke.

Objective

To compare stroke severity and outcomes regarding stroke victims with and without AF.

Methods

Analysis of the medical data (including age, sex, stroke type, localization, treatment method, severity and outcomes of the stroke (according to the National Institutes of Health Stroke Scale (NIHSS) score, Barthel index score, death), antithrombotic treatment) of 200 stroke patients (100 with $\mathrm{AF}, 100$ without $\mathrm{AF})$.

Results

Patients with AF were older than non-AF patients $(76.19 \pm 9.4$ vs. $66.99 \pm 11.7, \mathrm{p}<0.001)$, there were more women among them $(63 v s .39$, $\mathrm{p}=0.01$ ). 53 patients with AF had used anticoagulants (AC) before stroke (most of them were used ineffectively), 99 had had indications to use them. The distribution of the type of the stroke did not differ significantly between groups. AF patients had stroke in the area of the brain supplied by the carotid artery more often $(95 \%$ vs. $78 \%, p<0.001)$. Initial stroke severity ( $\mathrm{p}=0.006)$, NIHSS after thrombolysis ( $\mathrm{p}=0.008)$, NIHSS 7 days after thrombolysis $(\mathrm{p}=0.01)$ was higher in AF patients; Barthel index score $(\mathrm{p}=0.194)$ and mortality $(\mathrm{p}=0.323)$ did not differ.

\section{Conclusion}

Patients with AF experienced more severe strokes and presented higher neurologic deficits than patients without this condition. Nevertheless, the mortality and patients' final functional status did not differ. AC usage in patients with AF did not alleviate neurologic deficits and stroke outcomes possibly due to their insufficient usage.
\end{abstract}

Keywords: Atrial fibrillation, Stroke, Anticoagulation, Lithuania, NIHSS, Disease.

Article History Received: February 20, 2019

Revised: June 24, 2019

Accepted: July 12, 2019

\section{INTRODUCTION}

Stroke is the second leading cause of death and the third most preeminent cause of disability worldwide [1]. As a result of enhancing prophylaxis, diagnostics, more attainable and sufficient treatment stroke related mortality is abating, nevertheless stroke with its consequences still engender colossal economic, social and medical concerns which are only increasing [2]. According to the epidemiologic research over

\footnotetext{
* Address correspondence to this author at Faculty of Medicine, Lithuanian
} University of Health Sciences, Lithuania; E-mail: auguste.august@gmail.com the last two decades the incidence of stroke remains a relevant issue in Lithuania [3].

$\mathrm{AF}$ is a major risk factor for ischemic stroke (IS). It increases the risk of IS in all age groups, especially in the elderly $[4,5]$. The increasing incidence and prevalence of stroke and $\mathrm{AF}$ itself is related to the aging of population [6]. It is entrenched that the incidences of AF among patients with IS are surging rapidly and thus results in higher general fatality as well as particularly higher stroke mortality rates [7, 8]. Additionally, AF boosts health care and hospitalization expenditures, the usage of medical resources as well as the general 
economic burden which in itself is considerably weightful for stroke patients $[9,10]$. Therefore, it is vital to diagnose AF as soon as possible. Then, it is mandatory to evaluate the risk of thromboembolism (TE) (according to CHA2DS2-VASc score) and prescribe adequate preventive treatment (anticoagulants (AC)) to diminish not only the risk of IS, but also its severity and mortality rates [11]. Despite this in the real-life clinical practice AC are often either delayed or underused. This is mostly a result of hemorrhagic complications (especially intracranial bleeding) that threaten clinicians and patients [12].

A wide variety of researches have been conducted to evaluate the significance of $\mathrm{AF}$ in stroke development. However, in order to understand the connection of AF and stroke better, as well as to promote a more effective prevention of thromboembolic events, it is fundamental to conduct relevant researches that analyze AF's impact on stroke severity and outcomes. Objective of the study was to establish the differences of the characteristics of stroke and to compare its severity and outcomes regarding stroke victims with and without AF.

\section{MATERIALS AND METHODS}

\subsection{Study Population}

Two hundred randomly selected patients of the Department of Neurology of the Hospital of Lithuanian University of Health Sciences Kauno klinikos (LUHSH KC) that were hospitalized because of a stroke. One hundred of the patients were diagnosed with $\mathrm{AF}$ either during the hospitalization or previously, while others were AF-free. The randomisation process: 478 medical records of patients with stroke (marked with codes I61.0, I63 or I64 according to the International Statistical Classification of Diseases and Related Health Problems (ICD-10-AM)) were reviewed at the LUHSH KC department of Neurology. The records were analysed and divided into categories (143 records of patients with $\mathrm{AF}$ and 335 of patients without it) and those that lacked the necessary data were excluded. 101 records of patients with AF and 232 records of patients without $\mathrm{AF}$ remained and for the purpose of statistical clarity 100 records per arm were selected randomly. The research was conducted having the consent of Lithuanian University of Health Sciences (LUHS) Bioethics Committee (permission number BEC-MF-446).

\subsection{Data Compilation}

The analysis of medical data (from patients' medical documentation) was conducted after dividing the subjects into two categories: patients with $\mathrm{AF}$ and patients without AF. The data that we collected included patients' age, sex, stroke type (ischemic, hemorrhagic, ischemic with hemorrhagic transformation), stroke localization (an area of the brain supplied by a carotid artery or a vertebral-basilar artery), treatment method (thrombolysis or conservative), the severity of the stroke (according to the National Institutes of Health Stroke Scale (NIHSS) score before thrombolysis if it was used) and the stroke's outcomes (the NIHSS score immediately after and seven days after thrombolysis; the Barthel index score at the end of hospitalization; death). Additionally, we analyzed the usage of antithrombotic medications among our subjects prior to the stroke (Antiplatelet Drugs (AP), Anticoagulants (AC): Novel Oral Anticoagulants (NOACs) (rivaroxaban, dabigatran, apixaban) or Vitamin K Antagonists (VKA) (warfarin)). Moreover, we determined the condition of the coagulation system (International Normalized Ratio (INR) on the day of hospitalization) which also showed the efficiency of warfarin treatment if warfarin was prescribed (warfarin treatment was effective if INR ranged from 2 to 3 ). We also determined the risk factors for thromboembolic complications in both groups: Congestive Heart Failure (CHF) History, Hypertension (AH) History, Diabetes (DM) history, Peripheral Vascular Disease (PVD) or Myocardial Infarction (MI) history, stroke / Transient Ischemic Attack (TIA) / thromboembolism history; a CHA2DS2-VASc score was calculated. In addition, we evaluated the risk of bleeding (assuming hypertension, Renal Disease (RD), Liver Disease (LD), stroke history, previous major bleeding or predisposition to bleeding, labile INR, medication usage predisposing to bleeding, alcohol use) and calculated a HAS-BLED score. After evaluating these factors, we compared bleeding and TE risks as well as severity and outcomes of underwent strokes in patients with and without AF.

\subsection{Statistical Analysis}

The collected data was processed using Microsoft Excel 2007 and SPSS 22.0 software. The findings are presented as mean \pm standard deviation, if they meet the normality criteria and median (minimum-maximum) if they do not satisfy it. Frequencies are presented as percentages (\%) and they usually represent the real number of patients as there are a 100 of them in each group. To compare the two independent samples when they did not meet normality criteria, Mann-Whitney U test was used. When the data met normality criteria, two independent samples were compared by using Student $t$ test. Pearson ChiSquare test of homogeneity $\left(\chi^{2}\right)$ was used to analyze nominal values. A $p$ value of $<0.05$ was considered statistically significant.

\section{RESULTS}

\subsection{Clinical Characteristics}

The number of patients using antithrombotic medications was higher in AF group ( $66 \%$ vs. $20 \%, \mathrm{p}<0.001)$. In this group 14 patients were prescribed AP (12 got aspirin and 2 clopidogrel), $53 \mathrm{AC}$ (43 warfarin, 1 dabigatran, 6 rivaroxaban, 3 apixaban) before stroke. Only one of the patients who had not received any antithrombotic treatment had a CHA2DS2-VASc score that had not indicated antithrombotic treatment according to the European Society of Cardiology (ESC) guidelines [13]. These guidelines also defined that the only adequate treatment for TE prevention in patients with AF is AC. Knowing that, we divided the AF group into subgroups. One of them contained patients who had been treated with AC, and the other - those who had not been treated with AC. We analyzed their clinical characteristics separately (Table 1). In AF-free group 15 patients had used AP, 6 AC before stroke. 
Table 1. Clinical characteristics of patients with and without AF (distinguishing AF patients regarding AC usage before stroke).

\begin{tabular}{|c|c|c|c|c|c|c|}
\hline & \multirow[t]{2}{*}{ Non-AF patients } & \multirow[t]{2}{*}{ AF patients } & \multirow[t]{2}{*}{$p$ value } & \multicolumn{2}{|c|}{ Patients with AF } & \multirow[t]{2}{*}{ p value } \\
\hline & & & & Patients using AC $(n=53)$ & Patients without $\mathrm{AC}(\mathrm{n}=47)$ & \\
\hline Age, years & $66.99 \pm 11.7$ & $76.19 \pm 9.4$ & $<0.001$ & $74.32 \pm 7.67$ & $78.51 \pm 10.74$ & 0.022 \\
\hline $\begin{array}{l}\text { Sex } \\
\text { Men, n (\%) } \\
\text { Women, n (\%) }\end{array}$ & $\begin{array}{l}61(61) \\
39(39)\end{array}$ & $\begin{array}{l}37(37) \\
63(63)\end{array}$ & 0.01 & $\begin{array}{l}23(23) \\
30(30)\end{array}$ & $\begin{array}{l}14(14) \\
33(33)\end{array}$ & 0.159 \\
\hline INR* & $1(0.9-1.47)$ & $1.15(0.96-3.25)$ & $<0.001$ & $1.21(1-3.25)$ & $1.11(0.94-3.15)$ & $<0.001$ \\
\hline Stroke history, n (\%) & $11(11)$ & $18(18)$ & 0.160 & $9(9)$ & $9(9)$ & 0.778 \\
\hline
\end{tabular}

AF-atrial fibrillation; AC-anticoagulants; INR - international normalized ratio

*INR in AF patients using VKA was 1.22 (1-3.25), only four of these patients had INR in recommended therapeutic range (2-3).

Table 2. The risk of thromboembolism and bleeding in patients with and without AF.

\begin{tabular}{|c|c|c|c|}
\hline & Patients without AF & Patients with AF & p value \\
\hline $\begin{array}{c}\text { CHA2DS2-VASc score } \\
\text { CHF, n } \\
\text { AH, n } \\
\geq 75 \text { y., n } \\
65-74 \text { y., n } \\
\text { Stroke/ TIA/ TE history, n } \\
\text { PVD/ MI history, n } \\
\text { DM, n } \\
\text { Female, } \mathrm{n}\end{array}$ & $\begin{array}{c}3(0-7) \\
6 \\
84 \\
28 \\
32 \\
18 \\
12 \\
23 \\
39\end{array}$ & $\begin{array}{c}4(1-8) \\
9 \\
99 \\
55 \\
34 \\
22 \\
16 \\
8 \\
63\end{array}$ & $\begin{array}{c}<\mathbf{0 . 0 0 1} \\
0.421 \\
<\mathbf{0 . 0 0 1} \\
<\mathbf{0 . 0 0 1} \\
0.764 \\
0.480 \\
0.415 \\
\mathbf{0 . 0 0 3} \\
\mathbf{0 . 0 0 2}\end{array}$ \\
\hline $\begin{array}{c}\text { HAS-BLED score } \\
\text { AH, n } \\
\text { RD/ LD, n } \\
\text { Prior stroke, } \mathrm{n} \\
\text { Major bleeding history, } \mathrm{n} \\
\text { Labile INR, } \mathrm{n} \\
>65 \text { y., } \mathrm{n} \\
\text { Drugs/ alcohol, } \mathrm{n}\end{array}$ & $\begin{array}{c}2(0-4) \\
84 \\
3 \\
11 \\
\\
\\
57 \\
18\end{array}$ & $\begin{array}{c}2(1-4) \\
99 \\
9 \\
18 \\
\\
\\
88 \\
18\end{array}$ & $\begin{array}{c}<\mathbf{0 . 0 0 1} \\
<\mathbf{0 . 0 0 1} \\
0.150 \\
0.160 \\
- \\
- \\
<\mathbf{0 . 0 0 1} \\
0.493\end{array}$ \\
\hline
\end{tabular}

AF-atrial fibrillation; CHF-congestive heart failure; AH-hypertension; TIA-transient ischemic attack; TE-thromboembolism; PVD-peripheral vascular disease; MImyocardial infarction; DM-diabetes mellitus; RD-renal disease; LD-liver disease; INR - international normalized ratio.

We evaluated the risks of thromboembolism (CHA2DS2VASc score) and bleeding (HAS-BLED score) for AF and nonAF patients (Table 2). There were no statistically significant differences between these risks in AF patients' subgroups by treatment with AC: the treated ones had a CHA2DS2-VASc score median 3 (1-8), the untreated - 4 (1-7), $p=0.450$, a HASBLED score of the treated was 2 (1-3), of the untreated 2 (1-4), $\mathrm{p}=0.332$.

\subsection{Stroke Characteristics}

The distribution of the type of the stroke did not differ significantly between groups: $84 \%$ of the patients with AF had ischemic stroke $v s .90 \%$ for non-AF patients, $\mathrm{p}=0.207,9 \%$ of the AF patients had hemorrhagic stroke vs. $3 \%$ for patients without AF, $\mathrm{p}=0.074$, ischemic stroke with hemorrhagic transformation made up $7 \%$ in both groups, $p=1,000$. Stroke localization differed significantly: $95 \%$ of patients with AF had stroke in the area of the brain supplied by the carotid artery ( $v s$. $78 \%$ for patients without AF, $\mathrm{p}<0.001$ ) and only $5 \%$ in the area supplied by the vertebral-basilar artery (vs. $22 \%$ for patients without $\mathrm{AF}, \mathrm{p}<0.001)$. For patients with $\mathrm{AF}$ thrombolysis was performed more often $(66 \%$ vs. $59 \%$, p $<0.001)$.

The neurologic deficit was assessed according to the NIHSS score before, after and 7 days following thrombolysis, if it was performed. Stroke severity was determined based on the NIHSS score before stroke (0 points - no signs of stroke, 1-4 - minor stroke, 5-15 - moderate stroke,16-20 - moderate to severe, 21-42 - severe stroke). Stroke severity of patients without AF was: 6 had a minor stroke, 45 had a moderate one and 8 - a moderate to severe stroke. The patients with $\mathrm{AF}$ experienced 5 minor, 48 moderate, 11 moderate to severe and 2 severe strokes. Store was more severe in AF group and higher neurological deficit remained after and 7 days following thrombolysis (Table 3).

Table 3. Stroke severity and outcomes in patients with and without AF.

\begin{tabular}{|l|c|c|c|}
\hline & Patients without AF & Patients with AF & p value \\
\hline NIHSS score & $9(2-20)$ & $12(1-25)$ & $\mathbf{0 . 0 0 6}$ \\
Before thrombolysis & $4(1-19)$ & $8(1-22)$ & $\mathbf{0 . 0 0 8}$ \\
After thrombolysis & $2(0-18)$ & $5(0-22)$ & $\mathbf{0 . 0 1 0}$ \\
7 days after thrombolysis & & & \\
\hline
\end{tabular}


(Table 3) contd.....

\begin{tabular}{|c|c|c|c|}
\hline- & Patients without AF & Patients with AF & p value \\
\hline Barthel index score & $75(0-100)$ & $70(0-95)$ & 0.194 \\
\hline Death, n (\%) & $7(7)$ & $11(11)$ & 0.323 \\
\hline
\end{tabular}

AF-atrial fibrillation; NIHSS- the National Institutes of Health Stroke Scale.

Table 4. Stroke characteristics and outcomes of AF patients regarding AC usage before stroke.

\begin{tabular}{|l|c|c|}
\hline \multicolumn{1}{|c|}{-} & \multicolumn{2}{|c|}{ Patients with AF } \\
\cline { 2 - 3 } & Patients with AC (n=53) & Patients without AC (n=47) \\
\hline Stroke type & $43(43)$ & $41(41)$ \\
Ischemic, n (\%) & $6(6)$ & $3(3)$ \\
Hemorrhagic, n (\%) & $4(4)$ & $3(3)$ \\
Ischemic with hemorrhagic transformation, n (\%) & 0.406 \\
\hline Stroke localization & $50(50)$ & 0.820 \\
Carotid artery, n (\%) & $3(3)$ & $45(45)$ \\
Vertebral-basilar artery, n (\%) & 0.748 \\
\hline Thrombolysis, n (\%) & $31(31)$ & 0.747 \\
\hline NIHSS score & $11(1-25)$ & $35(35)$ \\
Before thrombolysis & $4(1-16)$ & $11(3-21)$ \\
After thrombolysis & $2(0-8)$ & $7(1-18)$ \\
7 days after thrombolysis & & $2(0-17)$ \\
\hline Barthel index score & & 0.239 \\
\hline Death, n (\%) & $65(35-90)$ & 0.830 \\
\hline
\end{tabular}

AF-atrial fibrillation; AC-anticoagulants; NIHSS- the National Institutes of Health Stroke Scale.

Additionally, we analyzed stroke characteristics and outcomes in subgroups of AF patients according to previous AC usage (Table 4).

\subsection{Characteristics of Stroke in Men and Women}

Finally, we compared the differences of all abovementioned data (age, INR, stroke history, HAS-BLED score, stroke type and localization, usage of thrombolysis, NIHSS score before thrombolysis, immediately and 7 days after it, Barthel index score, death) by sex regarding patients with and without AF (CHAD2DS2-VASc score was not compared as it is automatically higher for females). We noticed that the non$\mathrm{AF}$ men were younger than women in the same group (mean age $64.98 \pm 11.43$ vs. $70.13 \pm 11.56, \mathrm{p}=0.032$ ). In addition to this, these men had lower HAS-BLED score (1(0-4) vs. 2(0-4), $\mathrm{p}=0.042)$. The non-AF women more often had stroke history $(\mathrm{n}=8$ vs. $\mathrm{n}=3, \mathrm{p}=0.015)$ and TIA or other thromboembolic events in the past than the men in the same group $(\mathrm{n}=11 \mathrm{vs}$. $\mathrm{n}=7, \mathrm{p}=0.034)$, although the men had more PVD and MI $(\mathrm{n}=11$ vs. $\mathrm{n}=1, \mathrm{p}=0.02$ ). No statistically significant differences between men and women were identified in AF group.

\section{DISCUSSION}

Our findings showed that AF patients were older than nonAF patients, $\mathrm{p}<0.001$; there were more men without $\mathrm{AF}$ and more women with $\mathrm{AF}, \mathrm{p}=0.01$. This was reaffirmed by plenty of other research that emphasized AF-related stroke risk for the elderly: for example, the Framingham study showed that AF has five-fold higher risk for stroke and this remains with advancing age [4]. We also determined that patients with AF had a higher INR $(\mathrm{p}<0.001)$, which was most likely linked to the fact that these patients had received antithrombotic treatment prior stroke more frequently $(\mathrm{p}<0.001)$. Patients with AF who had received AC before stroke also had higher INR than untreated patients in this group, $\mathrm{p}<0.001$. According to our findings, stroke history was not more common in any group, although other studies suggested that the recurrence of stroke was more likely for patients with AF [14].

AF was associated with increased bleeding $(p<0.001)$ and TE $(\mathrm{p}<0.001)$ risk according to the HAS-BLED and CHAD2DS2-VASc scores. A more thorough analysis showed what components led to the differences of TE risk: there were more women $(p=0.002)$, more patients no younger than 75 years $(\mathrm{p}<0.001)$, more patients with $\mathrm{AH}(\mathrm{p}<0.001)$ in $\mathrm{AF}$ group. AH $(p<0.001)$ and older age $(p<0.001)$ in the AF group determined higher bleeding risk. CHAD2DS2-VASc and HASBLED scores did not differ between patients who had received $\mathrm{AC}$ prior stroke and those who had not in the AF group. This is explained by the fact that $97.06 \%$ of patients who had not received AC had had indications for it (CHAD2DS2-VASc score $\geq 1$ for men and $\geq 2$ for women) [13].

There was a link between stroke localization and AF $(\mathrm{p}<0.001)$. In addition to this, patients with AF were more often treated with intravenous thrombolysis than patients without it $(p<0.001)$. 2018 Guidelines for the early management of patients with acute ischemic stroke from the American Heart Association/American Stroke Association recommend that all eligible patients should receive intravenous thrombolysis without delay. Intravenous thrombolytic therapy improves functional outcomes, but has a lot of contraindications, one of which is linked to the usage of AC (INR $\geq 1.7$ when using warfarin or the intake of NOACs during the last 24 hours). It is extremely important that patients with AF who had received AC more often and had higher bleeding risk in general were still frequently treated with thrombolysis. Although the same rates of thrombolysis for patients who had and had not been treated with AC showed that antithrombotic treatment had been inadequate and ineffective (if it had been 
effective, thrombolysis would have been contraindicated). Another important highlight regarding pre-stroke antithrombotic treatment is that the usage of AC was not connected to higher rates of hemorrhagic stroke $(p=0.389)$, although it is an often feared complication. However, as the treatment was ineffective in most cases, the rate of complications and the reliability of this result are debatable.

Stroke was more severe (according to the NIHSS score before thrombolysis, $\mathrm{p}=0.006$ ) in AF group, the severity in this group remained higher after thrombolysis $(\mathrm{p}=0.008)$ and 7 days following it $(\mathrm{p}=0.010)$. In spite of this, no significant differences in final functional status (Barthel index score at the end of hospitalization) and no higher mortality rates were observed in any group. Other research showed that AF was associated with higher stroke severity, worse outcomes and higher mortality [14]. Stroke outcomes were not significantly different with or without AC, but this was likely due to the fact that most of the patients had not received adequate treatment with AC (only 4 patients using AC had INR $>2$, some of the patients using NOACs were not contraindicated for thrombolysis). There is evidence that $\mathrm{AC}$ not only reduces the frequency of stroke but also its severity and the risk of death [15].

There were sex related differences in the non-AF group: the men were younger than the women $(p=0.032)$, their bleeding risk was lower $(\mathrm{p}=0.032)$, they had PVD and MI more often $(p=0.02)$, but had experienced strokes $(p=0.015)$ and TIA or other thromboembolic complications $(\mathrm{p}=0.034)$ less often than the women.

\section{CONCLUSION}

Our study showed that patients with AF experienced more severe strokes and presented higher neurologic deficits than patients without this condition. Nevertheless, the mortality and patients' final functional status did not differ between groups. AC usage in patients with AF did not alleviate neurologic deficits and stroke outcomes possibly due to their insufficient usage (most of the patients with AF had indications for TE prevention, but only $53 \%$ had used AC before stroke and the usage was inadequate and ineffective in most cases).

\section{ETHICS APPROVAL AND CONSENT TO PARTICIPATE}

The research was conducted having the consent of LUHS Bioethics Committee (permission number BEC-MF-446).

\section{HUMAN AND ANIMAL RIGHTS}

No animals were involved in the research. Humans were not directly involved in the research. The collection of medical data of the participants was made with the permission of LUHS Bioethics Committee and the information was used according to the principles of the declaration of Helsinki.

\section{CONSENT FOR PUBLICATION}

Not applicable.

\section{AVAILABILITY OF DATA AND MATERIALS}

Not applicable.

\section{FUNDING}

We have not received any funding for the study except that Kaunas Region Society of Cardiology (a workplace of Vytautas Zabiela) agreed to pay the submission fee to publish the article.

\section{CONFLICT OF INTEREST}

The author declares no conflict of interest, financial or otherwise.

\section{ACKNOWLEDGEMENTS}

Declared none.

\section{REFERENCES}

[1] Lozano R, Naghavi M, Foreman K, et al. Global and regional mortality from 235 causes of death for 20 age groups in 1990 and 2010: A systematic analysis for the Global Burden of Disease Study 2010. Lancet 2012; 380(9859): 2095-128.

[http://dx.doi.org/10.1016/S0140-6736(12)61728-0] [PMID: 2324 5604]

[2] Feigin VL, Forouzanfar MH, Krishnamurthi R, et al. Global and regional burden of stroke during 1990-2010: Findings from the Global Burden of Disease Study 2010. Lancet 2014; 383(9913): 245-54. [http://dx.doi.org/10.1016/S0140-6736(13)61953-4] [PMID: 2444 9944]

[3] Rastenytė D, Radišauskas R, Bernotienė G, Šopagienė D, Jančaitytė L. Kauno gyventojų sergamumas ir mirtingumas nuo pagrindinių širdies ir kraujagyslių ligų 1983 - 2002 m 2003; 1(12)1208

[4] Wolf PA, Abbott RD, Kannel WB. Atrial fibrillation as an independent risk factor for stroke: The Framingham Study. Stroke 1991; 22(8): 983-8.

[http://dx.doi.org/10.1161/01.STR.22.8.983] [PMID: 1866765]

[5] Lip GYH, Brechin CM, Lane DA. The global burden of atrial fibrillation and stroke: A systematic review of the epidemiology of atrial fibrillation in regions outside North America and Europe. Chest 2012; 142(6): 1489-98.

[http://dx.doi.org/10.1378/chest.11-2888] [PMID: 22459778]

[6] Rahman F, Kwan GF, Benjamin EJ. Global epidemiology of atrial fibrillation. Nat Rev Cardiol 2014; 11(11): 639-54.

[http://dx.doi.org/10.1038/nrcardio.2014.118] [PMID: 25113750]

[7] Otite FO, Khandelwal P, Chaturvedi S, Romano JG, Sacco RL, Malik $\mathrm{AM}$. Increasing atrial fibrillation prevalence in acute ischemic stroke and TIA. Neurology 2016; 87(19): 2034-42.

[http://dx.doi.org/10.1212/WNL.0000000000003321] [PMID: 27733570]

[8] Benjamin EJ, Wolf PA, D'Agostino RB, Silbershatz H, Kannel WB, Levy D. Impact of atrial fibrillation on the risk of death: The Framingham Heart Study. Circulation 1998; 98(10): 946-52. [http://dx.doi.org/10.1161/01.CIR.98.10.946] [PMID: 9737513]

[9] Sussman M, Menzin J, Lin I, et al. Impact of atrial fibrillation on stroke-related healthcare costs. J Am Heart Assoc 2013; 2(6)e000479 [http://dx.doi.org/10.1161/JAHA.113.000479] [PMID: 24275631]

[10] Wen L, Wu J, Feng L, Yang L, Qian F. Comparing the economic burden of ischemic stroke patients with and without atrial fibrillation: A retrospective study in Beijing, China. Curr Med Res Opin 2017; 33(10): 1789-94.

[http://dx.doi.org/10.1080/03007995.2017.1348345]

[PMID: 28657348]

[11] Hylek EM, Go AS, Chang Y, et al. Effect of intensity of oral anticoagulation on stroke severity and mortality in atrial fibrillation. $\mathrm{N}$ Engl J Med 2003; 349(11): 1019-26.

[http://dx.doi.org/10.1056/NEJMoa022913] [PMID: 12968085]

[12] Lopes RD, Guimarães PO, Kolls BJ, et al. Intracranial hemorrhage in patients with atrial fibrillation receiving anticoagulation therapy. Blood 2017; 129(22): 2980-7.

[http://dx.doi.org/10.1182/blood-2016-08-731638] [PMID: 28356246]

[13] Benussi S. ESC GUIDELINES ESC Guidelines for the management of 
atrial fibrillation developed in collaboration with EACTS 2016

[14] Lin HJ, Wolf PA, Kelly-Hayes M, et al. Stroke severity in atrial fibrillation. The Framingham Study. Stroke 1996; 27(10): 1760-4 [http://dx.doi.org/10.1161/01.STR.27.10.1760] [PMID: 8841325]
[15] Hylek EM, Go AS, Chang Y, et al. Effect of intensity of oral anticoagulation on stroke severity and mortality in atrial fibrillation. $\mathrm{N}$ Engl J Med 2003; 349(11): 1019-26.

[http://dx.doi.org/10.1056/NEJMoa022913] [PMID: 12968085]

(C) 2019 Ragelytè et al.

This is an open access article distributed under the terms of the Creative Commons Attribution 4.0 International Public License (CC-BY 4.0), a copy of which is available at: (https://creativecommons.org/licenses/by/4.0/legalcode). This license permits unrestricted use, distribution, and reproduction in any medium, provided the original author and source are credited. 